Check for updates

Cite this: Chem. Commun., 2020, 56,12242

Received 9th May 2020,

Accepted 29th June 2020

DOI: $10.1039 / \mathrm{d} 0 \mathrm{cc} 03357 \mathrm{j}$

rsc.li/chemcomm

\section{Electroswitching of the single-molecule magnet behaviour in an octahedral spin crossover cobalt(II) complex with a redox-active pyridinediimine ligand +}

\author{
Renato Rabelo, ${ }^{a}$ Luminita Toma, ${ }^{\star a}$ Nicolás Moliner, (D) ${ }^{a}$ Miguel Julve, $\mathbb{D}^{a}$ \\ Francesc Lloret, (D) ${ }^{a}$ Jorge Pasán, (D) ${ }^{b}$ Catalina Ruiz-Pérez, (D) ${ }^{b}$ Rafael Ruiz-Garcia ${ }^{a}$ \\ and Joan Cano (iD *a
}

\begin{abstract}
Thermal-assisted spin crossover and field-induced slow magnetic relaxation coexist in the solid state for the mononuclear cobalt(II) complex with the non-innocent 2,6-bis( $N$-4-methoxyphenylformimidoyl)pyridine ligand. One-electron oxidation of the paramagnetic low-spin $\mathrm{Co}^{\prime \prime}$ ion $\left(S_{C o}=1 / 2\right)$ to the diamagnetic low-spin $C^{\prime \prime \prime I}$ ion $\left(S_{C o}=0\right)$ leads to the electroswitching of the slow magnetic relaxation in acetonitrile solution.
\end{abstract}

Metal complexes set up a promising way for the miniaturisation of electronic circuits leading to highly integrated electron spin-based systems for molecular spintronics and quantum computation. ${ }^{1}$ Combining many molecular magnetic components with multiresponsive and multifunctional abilities is necessary to build up molecular spintronic integrated circuits. ${ }^{2-8}$ In particular, redox-active mononuclear complexes exhibiting spin crossover (SCO) or single-molecule magnet (SMM) behaviour are of potential interest as electro-switchable molecular spintronic devices (spin transistors, rectifiers, and valves) and quantum devices (qubits and quantum gates). ${ }^{9-30}$

The combination of SCO and redox properties in one single molecule is allowed in the well-known bis-chelating cobalt(II) complexes with functionalised pyridine-2,6-diimine (PDI) ligands. ${ }^{31-34}$ The reduction of non-innocent PDI derivatives adds extra electronic features to the oxidizable metal centre in their complexes becoming molecular switches. Here we report the synthesis, structural and spectroscopic characterisation, electrochemical

\footnotetext{
${ }^{a}$ Instituto de Ciencia Molecular (ICMol), Universitat de València, 46980 Paterna, València, Spain.E-mail: luminita.toma@uv.es, joan.cano@uv.es

${ }^{b}$ Laboratorio de Rayos X y Materiales Moleculares, Departamento de Física, Universidad de La Laguna, 38201 Tenerife, Spain

$\dagger$ To the memory of Prof. Catalina Ruiz-Pérez, outstanding researcher and excellent teacher, best friend and colleague who passed away in August 2019. \# Electronic supplementary information (ESI) available: Experimental details on the synthesis of the ligand and complexes and their physicochemical characterisation (Fig. S1-S8, Scheme S1, and Tables S1-S3). CCDC 1989324 and 1989325. For ESI and crystallographic data in CIF or other electronic format see DOI: $10.1039 / \mathrm{d} 0 \mathrm{cc} 03357 \mathrm{j}$
}

and magnetic properties of a novel mononuclear cobalt(II) complex of formula $\left[\mathrm{Co}(4-\mathrm{MeOPhPDI})_{2}\right]\left(\mathrm{ClO}_{4}\right)_{2}(\mathbf{1})[4-\mathrm{MeOPhPDI}=$ 2,6-bis( $N$-4-methoxyphenylformimidoyl)pyridine] and its corresponding singly oxidised cobalt(III) derivative of formula [Co (4-MeOPhPDI $\left.)_{2}\right]\left(\mathrm{Br}_{3}\right)_{2.35}\left(\mathrm{Br}_{5}\right)_{0.65} \cdot 1 / 4 \mathrm{H}_{2} \mathrm{O}$ (2). To our knowledge, $\mathbf{1}$ is the first member of a new class of electroactive molecular nanomagnets that combine both SCO and SMM properties.

4-MeOPhPDI was synthesised from the straightforward condensation of pyridine-2,6-diformaldehyde and 4-anisidine (1:2 molar ratio) in diluted acetic acid media, as reported earlier for the parent unsubstituted PhPDI ligand. ${ }^{32}$ The reaction between cobalt(II) perchlorate hexahydrate and 4-MeOPhPDI (1:2 molar ratio) in methanol led to 1 . Subsequent chemical oxidation of 1 with an excess of bromine in acetonitrile resulted in 2. X-ray suitable single crystals of $\mathbf{1}$ and $\mathbf{2}$ were grown in a test tube by layering ethyl acetate on acetonitrile solutions (Fig. S1, ESI ).

1 and 2 crystallise in the $P_{3}$ and $I \overline{4} 2 \mathrm{~m}$ space groups of the tetragonal system, respectively (Table S1, ESI $\ddagger)$. The structures of 1 and 2 consist of mononuclear $\left[\mathrm{Co}^{\mathrm{II}}(4-\mathrm{MeOPhPDI})_{2}\right]^{2+}(\mathbf{1})$ and $\left[\mathrm{Co}^{\mathrm{III}}(4-\mathrm{MeOPhPDI})_{2}\right]^{3+}$ (2) complex cations (Fig. 1), perchlorate (1) or tri- and pentabromide (2) anions, and crystallisation water molecules (2). Unlike in 2, the mononuclear complex cations in $\mathbf{1}$ interact each other through relatively weak intermolecular "face-to-face" $\pi-\pi$ stacking interactions between the terminal $p$-methoxy-substituted phenyl rings $(h=$ 3.86-4.45 ̊; $\theta=16.3-26.8^{\circ}$ ) (Fig. S2 and S3, ESI $\ddagger$ ). The values of the shortest intermetallic distance through the "face-to-face" $\pi$-stacked units in 1 cover the range 9.359(1)-9.795(1) A, while they range from 9.698(2) to 11.193(2) ̊ in 2 .

The four crystallographically independent mononuclear cobalt(II) units of $\mathbf{1}$ exhibit an approximate $C_{2}$ molecular symmetry (Fig. 1a and Fig. S2, ESI $\ddagger$ ). Instead, 2 has a unique crystallographically independent mononuclear cobalt(III) unit with a crystallographically imposed $C_{2}$ molecular symmetry (Fig. 1b). The occurrence of moderate to strong, intramolecular "face-to-face" $\pi-\pi$ stacking interactions between the central pyridine and terminal phenyl rings of different ligands causes 
(a)

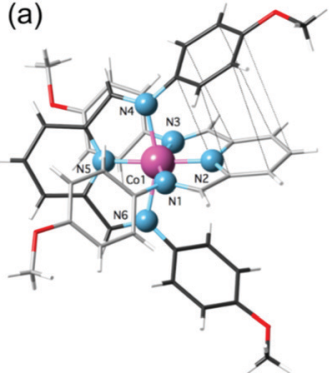

(b)

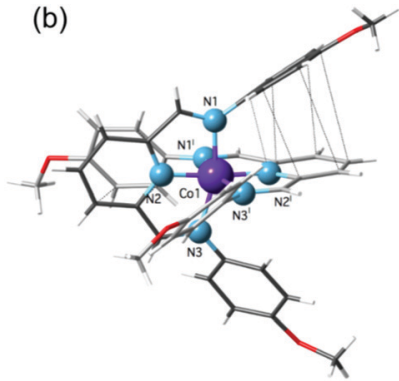

Fig. 1 Perspective views of the mononuclear cobalt(॥) and cobalt(॥I) cationic units of $\mathbf{1}$ (a) and $\mathbf{2}$ (b), respectively, with the atom numbering scheme for the first coordination sphere of the metal atoms [symmetry operation: $(I)=-x, y,-z]$. The intramolecular $\pi-\pi$ stacking interactions are drawn as dotted lines (each of the two ligand backbones are drawn in light and dark grey colours for clarity).

a distortion from orthogonality at the Co1 and Co3 atoms in 1 ( $h=3.84$ and $3.94 \AA$ and $\theta=23.5$ and $23.4^{\circ}$; Table S2, ESI $\ddagger$ ) and the Co1 atom in $2\left(h=3.91 \AA\right.$ and $\theta=22.9^{\circ}$; Table S2, ESI $\left.\ddagger\right)$. The value of the dihedral angle between the mean planes of the diiminomethylpyridine fragments in $2\left(\Phi=80.8^{\circ}\right)$ is intermediate between those found in $1[\Phi=72.2$ (Co1), 72.7 (Co3), and $89.9^{\circ}(\mathrm{Co} 2$ and $\left.\mathrm{Co} 4)\right]$.

All cobalt atoms in both $\mathbf{1}$ and 2 exhibit an axially compressed octahedral geometry. The equatorial plane is defined by the two pairs of imine nitrogen atoms $\left(\mathrm{N}_{\mathrm{im}}\right.$ and $\left.\mathrm{N}_{\mathrm{im}}{ }^{\prime}\right)$ from each ligand whereas the pyridine nitrogen $\left(\mathrm{N}_{\mathrm{py}}\right)$ atoms fill the axial positions (Fig. 1). Overall, the metal to nitrogen bond lengths in 1 and 2 are typical of low-spin (LS) $\mathrm{Co}^{\mathrm{II}}$ and $\mathrm{Co}^{\mathrm{III}}$ ions, respectively. The average values of the axial $\mathrm{Co}-\mathrm{N}_{\mathrm{py}}$ distances are notably shorter than those of the equatorial Co- $\mathrm{N}_{\mathrm{im}}$ ones for both $1\left[R_{\mathrm{ax}}=1.872(5)-1.940(5) \AA\right.$ and $R_{\mathrm{eq}}=$ $2.082(4)-2.146(4) \AA]$ and $2\left[R_{\mathrm{ax}}=1.841(8) \AA\right.$ and $\left.R_{\mathrm{eq}}=1.982(9) \AA\right]$.

The $\chi_{\mathrm{M}} T v s$. $T$ plot $\left(\chi_{\mathrm{M}}\right.$ being the dc molar magnetic susceptibility per mononuclear unit and $T$ the absolute temperature) for 1 reveals the presence of a gradual but complete, thermallyinduced SCO (Fig. 2), as reported earlier for the parent cobalt(II) complex with the unsubstituted PhPDI ligand. ${ }^{32}$ In both cases, no hysteresis occurs despite the occurrence of intermolecular

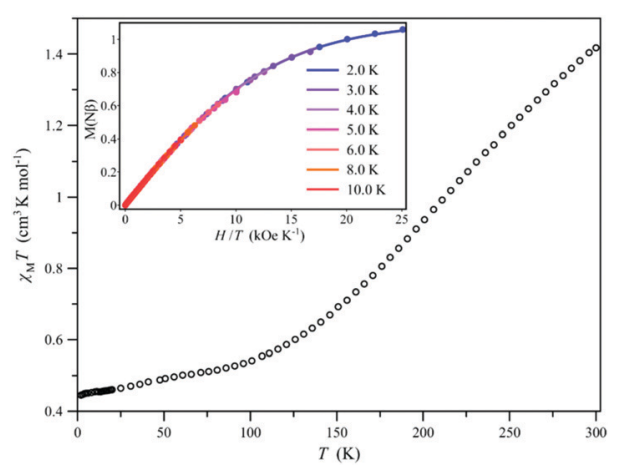

Fig. 2 Temperature dependence of $\chi_{M} T$ for 1 under applied dc magnetic fields of $0.25(T \leq 20 \mathrm{~K})$ and $5.0 \mathrm{kOe}(T>20 \mathrm{~K})$. The inset shows the field dependence of $M$ for 1 in the temperature range of 2.0-10.0 K. The solid line is the best-fit curve (see text). $\pi-\pi$ stacking interactions in the solid state. The $\chi_{\mathrm{M}} T$ value of $1.42 \mathrm{~cm}^{3} \mathrm{~mol}^{-1} \mathrm{~K}$ at room temperature is lower than that expected for a high-spin (HS) $\mathrm{Co}^{\mathrm{II}}$ ion with an unquenched orbital momentum contribution $\left(\chi_{\mathrm{M}} T=2.70 \mathrm{~cm}^{3} \mathrm{~mol}^{-1} \mathrm{~K}\right.$ with $S_{\text {Co }}=3 / 2$ and $g_{\text {Co }}=2.4$ ). Upon cooling, $\chi_{\mathrm{M}} T$ decreases smoothly to reach a sort of plateau around $100 \mathrm{~K}$ with a $\chi_{\mathrm{M}} T$ value of $0.45 \mathrm{~cm}^{3} \mathrm{~mol}^{-1} \mathrm{~K}$ at $2.0 \mathrm{~K}$, as expected for a $\mathrm{LS} \mathrm{Co}^{\mathrm{II}}$ ion $\left(\chi_{\mathrm{M}} T=\right.$ $0.45 \mathrm{~cm}^{3} \mathrm{~mol}^{-1} \mathrm{~K}$ with $S_{\mathrm{Co}}=1 / 2$ and $g_{\mathrm{Co}}=2.2$ ).

This conclusion is also supported by the $M$ vs. $H / T$ plots ( $M$ being the molar magnetisation per mononuclear unit and $H$ the applied dc magnetic field). Hence, they show: (i) a maximum value of $M$ about $1.00 \mathrm{~N} \beta$ at $H=50 \mathrm{kOe}$ and $T=2.0 \mathrm{~K}$ close to that for a LS Co ${ }^{\mathrm{II}}$ ion $\left(M=1.10 \mathrm{~N} \beta\right.$ with $\left.g_{\mathrm{Co}}=2.2\right)$; (ii) the superimposition of the reduced isothermal magnetisation curves in the temperature range of $2.0-10.0 \mathrm{~K}$; and (iii) the good simulation of these curves by the Brillouin function with $S_{\text {Co }}=1 / 2$ and $g_{\text {Co }}=2.20$ (inset of Fig. 2). On the other hand, the X-band EPR spectrum of 1 at $4.0 \mathrm{~K}$ in the solid state (Fig. 3) exhibits an axial signal $\left(g_{x}=g_{y}=2.09\right.$ and $\left.g_{z}=2.42\right)$, which is similar to that in frozen acetonitrile solutions $\left(g_{x}=g_{y}=2.08\right.$ and $g_{z}=2.37$ ). This situation is typical of a LS Co ${ }^{\mathrm{II}}$ ion with a $\mathrm{d}_{x^{2}-y^{2}}$ magnetic orbital, as expected for an axially compressed coordination geometry, both in the solid state and in solution.

The $\chi_{M}{ }^{\prime}$ and $\chi_{M}{ }^{\prime \prime} v s . \nu$ plots of $\mathbf{1}\left(\chi_{M}{ }^{\prime}\right.$ and $\chi_{M}{ }^{\prime \prime}$ being the inphase and out-of-phase ac molar magnetic susceptibilities per mononuclear unit) are characteristic of field-induced SMMs, both in the solid state and in frozen acetonitrile solutions. In this regard, there are two related examples of square-pyramidal mononuclear SCO cobalt(II) complexes exhibiting a fieldinduced SMM behaviour in the solid state, ${ }^{35,36}$ which have been proposed as promising candidates to molecular electron spin-based quantum bits (qubits). ${ }^{37}$

Neither frequency dependence of $\chi_{M}{ }^{\prime}$ nor a $\chi_{M}{ }^{\prime \prime}$ signal are observed in the absence of a dc magnetic field (data not shown). Some authors usually explain these features by a rapid relaxing (RR) spin featuring a fast quantum tunnelling of magnetisation (QTM). ${ }^{35,36}$ However, this phenomenon requires a barrier, which is not possible for a doublet spin ground state,

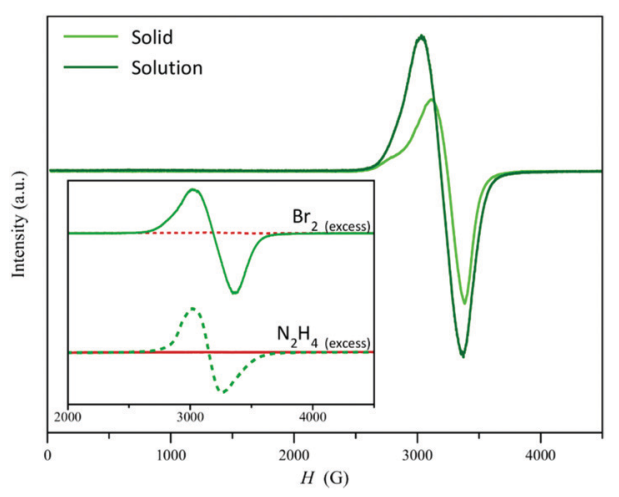

Fig. $3 \mathrm{X}$-band EPR spectra of 1 at $4.0 \mathrm{~K}$, both in the solid state (pale green line) and in a frozen acetonitrile solution (dark green line). The inset shows the $\mathrm{X}$-band EPR spectra of $\mathbf{1}$ and $\mathbf{2}$ at $4.0 \mathrm{~K}$ in frozen acetonitrile solution (green and red solid lines), compared with those of the corresponding in situ monoxidised and monoreduced species (red and green dotted lines). 
as in 1. Frequency-dependent $\chi_{\mathrm{M}}{ }^{\prime}$ and $\chi_{\mathrm{M}}{ }^{\prime \prime}$ signals arise by applying a magnetic field $\left(H_{\mathrm{dc}}=1.0,2.5\right.$ and $5.0 \mathrm{kOe}$ in solid state and $2.5 \mathrm{kOe}$ in solution) in agreement with the occurrence of a field-induced slow relaxing (SR) LS Co ${ }^{\mathrm{II}}$ ion (Fig. S5 and S6, ESI ). Hence, incipient signals develop at the $\chi_{\mathrm{M}}{ }^{\prime \prime} v s . \nu$ plots with decreasing temperature, both in the solid state and in solution. Additionally, in both conditions, a distinct maximum appears at the $\chi_{\mathrm{M}}{ }^{\prime \prime} v s . \nu$ plots that progressively shifts toward lower frequencies of the oscillating ac magnetic field as temperature decreases. This maximum occurs even at a higher temperature in solution. Consequently, the field-induced SR behaviour is not only retained but enhanced in frozen acetonitrile solutions relative to the solid state.

The values of the magnetic relaxation time $(\tau)$ were calculated from the joint analysis of the $\chi_{\mathrm{M}}{ }^{\prime}$ and $\chi_{\mathrm{M}}{ }^{\prime \prime} v s . \nu$ plots through the generalised Debye equations, which consider the static $\left(\chi_{\mathrm{S}}\right)$ and infinite $\left(\chi_{\mathrm{T}}\right)$ frequency magnetic susceptibilities, and the exponential factor that describes the broadness of the spectra $(\alpha)$, as additional fitting parameters (Fig. S7, ESI $\ddagger$ ). The results displayed as $\ln \tau$ vs. $1 / T$ graphs (Arrhenius plots) were satisfactorily simulated considering a simple magnetic two-phonon Raman relaxation mechanism, $\tau^{-1}=C T^{n}$ (Fig. 4). However, in the range of lower temperatures, at $5.0 \mathrm{kOe}$ in solid state and $2.5 \mathrm{kOe}$ in solution, required the inclusion of an extra relaxation process. Unexpectedly, this additional process was not a one-phonon direct mechanism, ${ }^{35,36}$ but a temperatureindependent term $\left(\tau^{-1}=k\right)$. This contribution to the spin-reversal relaxation should occur within the Zeeman-split $m_{\mathrm{S}}= \pm 1 / 2$ Kramers ground doublet and should be seen as a zero-order term of a direct mechanism and not as a QTM process inconsistent with an $S=1 / 2$ spin ground state. This $H_{\mathrm{dc}}$ dependent component should be notable in the lack of an applied magnetic field and, therefore, responsible for the zero-field RR behaviour.

The calculated values of the coefficients of the $\tau^{-1}=C T^{n}+k$ model appear summarised in Table S3 (ESI $\$$ ). The low values of $n$ (1.87-2.45) justify the needless inclusion of a first-order direct relaxation term $\left(\tau^{-1}=A T\right)$ and suggest the presence of optical

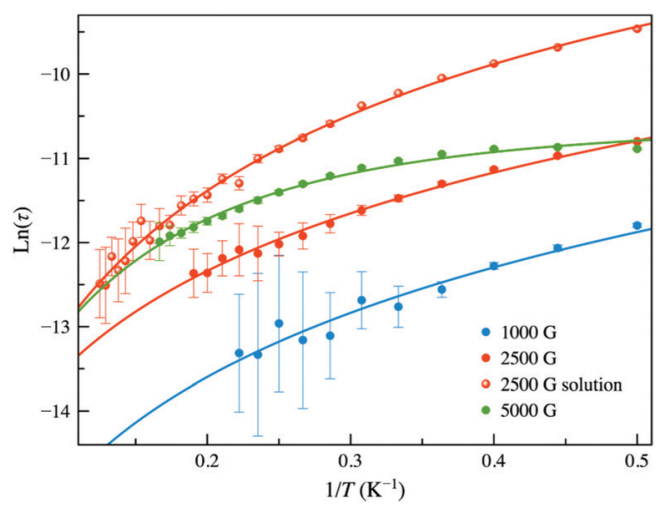

Fig. 4 Arrhenius plots of 1 under applied dc magnetic fields of 1.0, 2.5 and $5.0 \mathrm{kOe}$ in the solid state and $2.5 \mathrm{kOe}$ in solution. The solid lines are the best-fit for a double relaxation mechanism described by the equation $\tau^{-1}=$ $C T^{n}+k$ (see text). Vertical error bars denote the standard deviations.

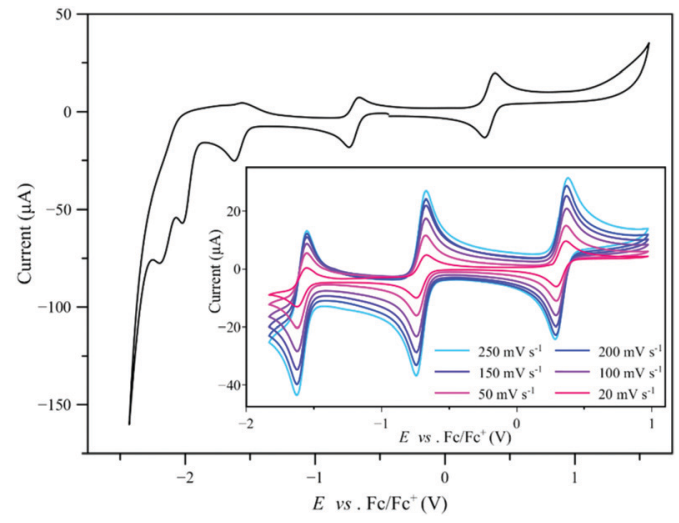

Fig. 5 Cyclic voltammograms of 1 in acetonitrile $\left(0.1 \mathrm{MnBu}_{4} \mathrm{NPF}_{6}\right)$ at $25^{\circ} \mathrm{C}$ and $200 \mathrm{mV} \mathrm{s}^{-1}$. The inset shows the cyclic voltammograms of the reversible redox waves in the scan rate range of $20-250 \mathrm{mV} \mathrm{s}^{-1}$.

rather than acoustic phonons. For the Raman mechanism, the similarity between the results in solution and the solid state at a larger magnetic field could lie in a decrease of the effects of the network when $H_{\mathrm{dc}}$ is increased.

The cyclic voltammograms of $\mathbf{1}$ in acetonitrile at room temperature show one reversible oxidation wave at $E_{1}=+0.39 \mathrm{~V}$ vs. the ferricinium/ferrocene $\left(\mathrm{Fc}^{+} / \mathrm{Fc}\right)$ couple, together with up to four reduction waves at $E_{2}=-0.74 \mathrm{~V}, E_{3}=-1.62 \mathrm{~V}, E_{4}=-2.02 \mathrm{~V}$, and $E_{5}=-2.19 \mathrm{~V}$, where only the two first ones are reversible (Fig. 5). This conclusion is supported by: (i) the values of the anodic to cathodic peak separation of these three reversible redox waves $\left(\Delta E_{\mathrm{p}, 1}=83 \mathrm{mV}, \Delta E_{\mathrm{p}, 2}=81 \mathrm{mV}\right.$ and $\left.\Delta E_{\mathrm{p}, 3}=77 \mathrm{mV}\right)$, which are comparable to that of the $\mathrm{Fc}^{+} / \mathrm{Fc}$ couple $\left(\Delta E_{\mathrm{p}}=80 \mathrm{mV}\right)$ under the same conditions (inset of Fig. 5), and (ii) the linearity of the peak current against the square root of the scan rate plots for each of them (data not shown).

The assignment of the observed redox processes for $\mathbf{1}$ is illustrated in Scheme S1 (ESI $\$$ ). ${ }^{34}$ The reversible oxidation wave corresponds to the one-electron metal oxidation to afford the cobalt(III) species, while the first pair of reversible reduction waves conforms to the stepwise one-electron reduction of the ligands to give the single and double imide-type $\pi$-radical anion cobalt(II) species. That being so, the second pair of irreversible reduction waves is likely attributed to the further stepwise oneelectron reduction of the ligands to give the single and double imide-type dianion cobalt(II) species. Both the $\sigma$-donor capacity of the electron-donating methoxy ligand substituents at the terminal phenyl groups and the $\pi$-acceptor ability of the central pyridinediimine ligand fragment are the leading cause of this dual metal- and ligand-centred multiredox behaviour of 1 .

The reversible interconvertion between the paramagnetic cobalt(II) complex and the diamagnetic cobalt(III) derivative has been monitored through X-band EPR spectra in solution (inset of Fig. 3). Upon addition of an excess of bromine to an acetonitrile solution of 1, the axial EPR signal of the paramagnetic $\mathrm{LS} \mathrm{Co}^{\mathrm{II}}$ ion $\left(S_{\mathrm{Co}}=1 / 2\right)$ disappears to give the corresponding EPR-silent diamagnetic LS Co ${ }^{\text {III }}\left(S_{\mathrm{Co}}=0\right)$ oxidised species. Conversely, the axial EPR signal of $\mathbf{1}$ is restored by addition of a stoichiometric amount of hydrazine to an acetonitrile solution of 2 . 
A solution of $\mathbf{1}$ in acetonitrile at $0{ }^{\circ} \mathrm{C}$ was subjected to electrochemical oxidation $\left(E_{\mathrm{ox}}=+1 \mathrm{~V}\right)$ and subsequent reduction $\left(E_{\text {red }}=0 \mathrm{~V}\right)$ (Fig. S4, ESI $\$$ ). Notably, the slow magnetic relaxation is preserved, the $\chi_{\mathbf{M}}{ }^{\prime}$ and $\chi_{M}{ }^{\prime \prime} v s$. $T$ plots before and after the electrolysis cycle being almost identical (Fig. S8, ESI $\ddagger$ ). In both cases, distinct $\chi_{M}{ }^{\prime}$ and $\chi_{M}{ }^{\prime \prime}$ maxima appear and progressively shift toward higher temperatures as far as the frequency of the oscillating ac magnetic field increases. This reversible response demonstrates that this interconvertible system works as a genuine molecular magnetic electroswitch in solution, even if it proceeds as two different compounds in the solid state.

In summary, we report a unique example of mononuclear cobalt(II) complex with a non-innocent pyridinediimine (PDI) ligand that exhibits both thermal-assisted LS-HS and fieldinduced RR-SR transitions. Moreover, it shows a dual redox behaviour featuring one-electron oxidation of the slow-relaxing paramagnetic $\mathrm{LS} \mathrm{Co}^{\mathrm{II}}$ ion $\left(S_{\mathrm{Co}}=1 / 2\right)$ to the diamagnetic $\mathrm{LS} \mathrm{Co}^{\mathrm{III}}$ ion $\left(S_{\mathrm{Co}}=0\right)$ and stepwise two-electron reduction of the PDI ligands to the corresponding imide-type $\mathrm{PDI}^{\bullet-} \pi$-radical anion and $\mathrm{PDI}^{2-}$ dianion. This new class of triply thermal-, magneto-, and electro-switchable molecular nanomagnet possesses multiple metal- or ligand-based, redox and spin states, which reversibly interconvert under different external stimuli (temperature, magnetic field, and redox potential). The reported magnetic and electronic multistability in this mononuclear cobalt(II)-PDI complex illustrates the potential of multiresponsive and multifunctional SCO/SMM molecules in the emerging fields of molecular spintronics and quantum computation.

This work was supported by the Spanish MINECO (Projects PID2019-109735GB-I00, CTQ2016-75068P, MAT2017-89203-R, and Unidad de Excelencia María de Maeztu MDM-2015-0538). This work has received funding from the European Union's Horizon 2020 research and innovation programme under the Marie Skłodowska-Curie grant agreement No 748921-SIMOF. R. R. and J. P. thank the Generalitat Valenciana and the Cabildo de Tenerife for a doctoral grant (GRISOLIAP/2017/057) and the Agustín de Betancourt research contract, respectively. We are indebted to Drs Marta Viciano-Chumillas and Gloria Agustí (Universitat de València) for the assistance in the electrochemical and EPR spectroscopic measurements.

\section{Conflicts of interest}

There are no conflicts to declare.

\section{Notes and references}

1 J. Ferrando-Soria, J. Vallejo, M. Castellano, J. Martínez-Lillo, E. Pardo, J. Cano, I. Castro, F. Lloret, R. Ruiz-García and M. Julve, Coord. Chem. Rev., 2017, 339, 17.

2 A. Dei, D. Gatteschi, C. Sangregorio and L. Sorace, Acc. Chem. Res., 2004, 37, 827.

3 O. Sato, J. Tao and E.-J. Zhang, Angew. Chem. Int. Ed., 2007, 46, 2152.

4 M. Castellano, R. Ruiz-García, J. Cano, J. Ferrando-Soria, E. Pardo, F. R. Fortea-Pérez, S. Eddine-Stiriba, M. Julve and F. Lloret, Acc. Chem. Res., 2015, 48, 510.
5 B. Sarkar, D. Schweinfurth, N. Deibel and F. Weisser, Coord. Chem. Rev., 2015, 293-294, 250.

6 D. Aguilà, Y. Prado, E. S. Koumousi, C. Mathonière and R. Clérac, Chem. Soc. Rev., 2016, 45, 203.

7 M. M. Khusniyarov, Chem. - Eur. J., 2016, 22, 15178; B. Doistau, L. Benda, B. Hasenknopf, V. Marvaud and G. Vives, Magnetochemistry, 2018, 4, 1.

8 Y.-S. Meng and T. Liu, Acc. Chem. Res., 2019, 52, 1369.

9 J. J. Parks, A. R. Champagne, T. A. Costi, W. W. Shum, A. N. Pasupathy, E. Neuscamman, S. Flores-Torres, P. S. Cornaglia, A. A. Aligia, C. A. Balseiro, G.-K.-L. Chan, H. D. Abruña and D. C. Ralph, Science, 2010, 328, 1370.

10 V. Meded, A. Bagrets, K. Fink, R. Chandrasekar, M. Ruben, F. Evers, A. Bernand-Mantel, J. S. Seldenthuis, A. Beukman and H. S. J. van der Zant, Phys. Rev. B: Condens. Matter Mater. Phys., 2011, 83, 245415.

11 T. Mahfoud, G. Molnár, S. Cobo, L. Salmon, C. Thibault, C. Vieu, P. Demont and A. Bouseksou, Appl. Phys. Lett., 2011, 99, 053307.

12 P. Verma, J. Weir, L. Mirica and T. D. Stack, Inorg. Chem., 2011, 50, 9816; D. Aravena and E. Ruiz, J. Am. Chem. Soc., 2012, 134, 777.

13 M. G. Cowan, J. Olguín, S. Narayanaswamy, J. L. Tallon and S. Brooker, J. Am. Chem. Soc., 2012, 134, 2892.

14 E. Ruiz, Phys. Chem. Chem. Phys., 2014, 16, 14.

15 G. D. Harzmann, R. Frisenda, H. S. J. van der Zant and M. Mayor, Angew. Chem. Int. Ed., 2015, 54, 13425.

16 E. J. Devid, P. N. Martinho, M. V. Kamalakar, I. Salitros, U. Prendergast, J.-F. Dayen, V. Meded, T. Lemma, R. GonzálezPrieto, F. Evers, T. E. Keyes, M. Ruben, B. Doudin and S. J. van der Molen, ACS Nano, 2015, 9, 4496.

17 A. C. Aragonès, D. Aravena, J. I. Cerdá, Z. Acís-Castillo, H. Li, J. A. Real, F. Sanz, J. Hihath, E. Ruiz and I. Díez-Pérez, Nano Lett., 2016, 16, 218.

18 A. C. Aragonès, D. Aravena, F. J. Valverde-Muñoz, J. A. Real, F. Sanz, J. Hihath, I. Díez-Pérez and E. Ruiz, J. Am. Chem. Soc., 2017, 139, 5768.

19 T. Jasper-Toennies, M. Gruber, S. Karan, H. Jacob, F. Tuczek and R. Berndt, Nano Lett., 2017, 17, 6613.

20 L. D. Wickramasinghe, S. Mazumder, K. K. Kpogo, R. J. Staples, H. B. Schlegel and C. N. Verani, Chem. - Eur. J., 2016, 22, 10876.

21 N. Ishikawa, M. Sugita, N. Tanaka, T. Ishikawa, S.-Y. Koshihara and Y. Kaizu, Inorg. Chem., 2004, 43, 5498.

22 S. Takamatsu, T. Ishikawa, S.-Y. Koshihara and N. Ishikawa, Inorg. Chem., 2007, 46, 7250.

23 S. Kyatskaya, J. R. Galán-Mascarós, L. Bogani, F. Hennrich, M. Kappes, W. Wernsdorfer and M. Ruben, J. Am. Chem. Soc., 2009, 131, 15143.

24 M. Urdampilleta, S. Klyatskaya, J.-P. Cleuziou, M. Ruben and W. Wernsdorfer, Nat. Mater., 2011, 10, 502.

25 R. Vincent, S. Klyatskaya, M. Ruben, W. Wernsdorfer and F. Balestro, Nature, 2012, 488, 357.

26 M. Ganzhorn, S. Klyatskaya, M. Ruben and W. Wernsdorfer, Nat. Nanotechnol., 2013, 8, 165.

27 E. M. Fatila, M. Roùzieres, M. C. Jennings, A. J. Lough, R. Clérac and K. E. Preuss, J. Am. Chem. Soc., 2013, 135, 9596.

28 L. Norel, M. Feng, K. Bernot, T. Roisnel, T. Guizouarn, K. Costuas and S. Rigaut, Inorg. Chem., 2014, 53, 2361.

29 M. Damjanovic, T. Morita, K. Katoh, M. Yamashita and M. Enders, Chem. - Eur. J., 2015, 21, 14421.

30 M. A. Antunes, J. T. Coutinho, I. C. Santos, J. Marçalo, M. Almeida, J. J. Baldoví, L. C. J. Pereira, A. Gaita-Ariño and E. Coronado, Chem. Eur. J., 2015, 21, 17817.

31 P. E. Figgins and D. H. Busch, J. Am. Chem. Soc., 1960, 82, 820.

32 G. Juhász, S. Hayami, K. Inoue and Y. Maeda, Chem. Lett., 2003, 32, 882.

33 B. De Bruin, E. Bill, E. Bothe, T. Weyhermüller and K. Wieghardt, Inorg. Chem., 2000, 39, 2936.

34 C. Römelt, T. Weyhermüller and K. Wieghardt, Coord. Chem. Rev., 2019, 380, 287.

35 H.-H. Cui, J. Wang, X.-T. Chen and Z.-L. Xue, Chem. Commun., 2017, 53, 930.

36 L. Chen, J. Song, W. Zhao, G. Yi, Z. Zhou, A. Yuan, Y. Song, Z. Wang and Z.-W. Ouyang, Dalton Trans., 2018, 47, 16596.

37 M.-X. Xu, Z. Liu, B.-W. Dong, H.-H. Cui, Y.-X. Wang, J. Su, Z. Wang, Y. Song, X.-T. Chen, S.-D. Jiang and S. Gao, Inorg. Chem., 2019, 58,2330 . 